\title{
Influenza Vaccination Recommendations During Use of Select Immunosuppressants for Psoriasis
}

\author{
Joyce Y. Kim, BS; Harry Dao Jr, MD
}

\section{PRACTICE POINTS}

- Patients receiving methotrexate appear to benefit from suspending treatment for 2 weeks following influenza vaccination, as it maximizes the seroprotective response.

- Patients receiving tumor necrosis factor $\alpha$ inhibitors and low-dose IL-17 inhibitors have an unaltered humoral response to vaccination and attain protection equal to that of the general population.

- Patients treated with cyclosporine should be closely monitored for influenza symptoms even after vaccination, as approximately half of patients do not achieve a seroprotective response.

- Consider the increased risk for psoriatic flare during treatment suspension and the possibility of failed seroprotection, warranting close monitoring and clinical judgement tailored to each individual.

$\Lambda$ 42-year-old woman with psoriasis presents for a checkup at the dermatology clinic. Her psoriasis has been fairly stable on methotrexate with no recent flares. She presents her concern of the coronavirus pandemic continuing into the flu season and mentions she would like to minimize her chances of having a respiratory illness. The influenza vaccine has just become available, and she inquires when she can get the vaccine and whether it will interfere with her treatment. What are your recommendations for the patient?
Psoriasis is an immune-mediated, inflammatory skin condition stemming from hyperproliferation of keratinocytes that classically involves erythematous skin plaques with overlying scale. Treatment options vary widely and include topical modalities, phototherapy, immunosuppressants, and biologic agents. Selection of treatment largely depends on the severity and extent of body surface area involvement; systemic therapy generally is indicated when the affected body surface area is greater than $5 \%$ to $10 \%$. In patients on systemic therapy, increased susceptibility to infection is a priority concern for prescribing physicians. In the context of continuing immunosuppressive medications, vaccines that reduce susceptibility to infectious diseases can play an important role in reducing morbidity and mortality for these patients; however, an important consideration is that in patients with chronic conditions and frequent hospital visits, vaccines may be administered by various clinicians who may not be familiar with the management of immunosuppressive treatments. It is pivotal for prescribing dermatologists to provide appropriate vaccination instructions for the patient and any future clinicians to ensure vaccine efficacy in these patients.

The intramuscular influenza vaccine is a killed vaccine that is administered annually and has been shown to be safe for use in both immunocompetent and immunocompromised patients. ${ }^{1,2}$ Despite its safety, questions remain regarding the efficacy of vaccines while a patient is unable to mount a normal immune response and whether the treatment must be altered to maximize immunogenicity. The common systemic treatment options for psoriasis

Ms. Kim is from the University of California, Riverside School of Medicine. Dr. Dao is from the Department of Dermatology, Loma Linda University, California.

The authors report no conflict of interest.

Correspondence: Joyce Y. Kim, BS, 900 University Ave, Riverside, CA 92521 (joyce.kim@medsch.ucr.edu).

doi:10.12788/cutis.0089 


\begin{tabular}{lll}
\hline Influenza Vaccination Recommendations for Psoriasis Patients Undergoing Treatment \\
\hline $\begin{array}{l}\text { Treatment } \\
\begin{array}{l}\text { Calcineurin inhibitors } \\
\text { (cyclosporine) }\end{array}\end{array}$ & $\begin{array}{l}\text { Reduced humoral response with nonprotective } \\
\text { titers in approximately } 50 \% \text { of patients } \\
\text { regardless of booster administration }\end{array}$ & $\begin{array}{l}\text { No need to alter therapy, but closely monitor for } \\
\text { symptoms; administer vaccine irrespective of } \\
\text { last dose }\end{array}$ \\
\hline $\begin{array}{l}\text { IL-17 pathway inhibitors } \\
\text { (secukinumab) }\end{array}$ & $\begin{array}{l}\text { No substantial humoral response at low dose } \\
\text { of } 150 \text { mg }\end{array}$ & $\begin{array}{l}\text { No need to alter therapy for vaccination; } \\
\text { administer vaccine irrespective of last dose }\end{array}$ \\
\hline $\begin{array}{l}\text { IL-23 and related } \\
\text { cytokine inhibitors }\end{array}$ & Insufficient data & Insufficient data \\
\hline $\begin{array}{l}\text { Methotrexate } \\
\text { Reduced humoral response to vaccine }\end{array}$ & $\begin{array}{l}\text { Administer vaccine irrespective of last dose; } \\
\text { suspending treatment for } 2 \text { wk following } \\
\text { vaccination has been shown to increase } \\
\text { seroprotective titers by 10\%-15\% in patients }\end{array}$ \\
\hline $\begin{array}{l}\text { Tumor necrosis factor } \alpha \\
\text { inhibitors (ie, etanercept, } \\
\text { infliximab, adalimumab) }\end{array}$ & No substantial humoral response & No need to alter therapy for vaccination; \\
\hline
\end{tabular}

and any recommendations that can be made regarding administration of the influenza vaccine in that context are outlined in the Table. Given the sparsity of clinical data measuring vaccine immunogenicity in patients with psoriasis, vaccine guidelines are drawn from patients with various conditions who are receiving the same dose of medication as indicated for psoriasis.

Immunosuppressants and biologics commonly are used in dermatology for the management of many conditions, including psoriasis. As flu season approaches in the setting of a global pandemic, it is critical to understand the effects of commonly used psoriasis medications on the influenza vaccine. Through a brief review of the latest data concerning their interactions, dermatologists will be able to provide appropriate recommendations that maximize a patient's immune response to the vaccine while minimizing adverse effects from holding medication.

\section{REFERENCES}

1. Zbinden $D$, Manuel $O$. Influenza vaccination in immunocompromised patients: efficacy and safety. Immunotherapy. 2014;6:131-139.

2. Milanovic M, Stojanovich L, Djokovic A, et al. Influenza vaccination in autoimmune rheumatic disease patients. Tohoku J Exp Med. 2013;229:29-34

3. Dengler TJ, Strnad N, Bühring I, et al. Differential immune response to influenza and pneumococcal vaccination in immunosuppressed patients after heart transplantation. Transplantation. 1998;66:1340-1347.

4. Willcocks LC, Chaudhry AN, Smith JC, et al. The effect of sirolimus therapy on vaccine responses in transplant recipients. Am J Transplant. 2007;7:2006-2011.

5. Chioato A, Noseda E, Stevens M, et al. Treatment with the interleukin17A-blocking antibody secukinumab does not interfere with the efficacy of influenza and meningococcal vaccinations in healthy subjects: results of an open-label, parallel-group, randomized single-center study, Clin Vaccine Immunol. 2012;19:1597-1602.

6. Richi P, Martín MD, de Ory F, et al. Secukinumab does not impair the immunogenic response to the influenza vaccine in patients. RMD Open. 2019;5:e001018.

7. FurerV, Zisman D, Kaufman I, et al. Immunogenicity and safety of vaccination against seasonal influenza vaccine in patients with psoriatic arthritis treated with secukinumab. Vaccine. 2020;38:847-851.

8. Hua C, Barnetche T, Combe B, et al. Effect of methotrexate, anti-tumor necrosis factor $\alpha$, and rituximab on the immune response to influenza and pneumococcal vaccines in patients with rheumatoid arthritis: a systematic review and meta-analysis. Arthritis Care Res. 2014;66: 1016-1026.

9. Park JK, Choi Y, Winthrop KL, et al. Optimal time between the last methotrexate administration and seasonal influenza vaccination in rheumatoid arthritis: post hoc analysis of a randomised clinical trial. Ann Rheum Dis. 2019;78:1283-1284.

10. Park JK, Lee MA, Lee EY, et al. Effect of methotrexate discontinuation on efficacy of seasonal influenza vaccination in patients with rheumatoid arthritis: a randomised clinical trial. Ann Rheum Dis. 2017;76:1559-1565

11. Park JK, Lee YJ, Shin K, et al. Impact of temporary methotrexate discontinuation for 2 weeks on immunogenicity of seasonal influenza vaccination in patients with rheumatoid arthritis: a randomised clinical trial. Ann Rheum Dis. 2018;77:898-904.

12. Shirai S, Hara M, Sakata $Y$, et al. Immunogenicity of quadrivalent influenza vaccine for patients with inflammatory bowel disease undergoing immunosuppressive therapy. Inflamm Bowel Dis. 2018;24:1082-1091.

13. Fomin I.Vaccination against influenza in rheumatoid arthritis: the effect of disease modifying drugs, including TNF blockers. Ann Rheum Dis. 2006;65:191-194

14. Bosaeed M, Kumar D. Seasonal influenza vaccine in immunocompromised persons. Hum Vaccin Immunother. 2018;14:1311-1322.

15. Kaine JL, Kivitz AJ, Birbara C, et al. Immune responses following administration of influenza and pneumococcal vaccines to patients with rheumatoid arthritis receiving adalimumab. J Rheumatol. $2007 ; 34: 272-279$ 